\title{
Reorganização do Movimento Estudantil: o Movimento Estudantil no CEFD/UFSM ${ }^{1}$
}

\author{
Reorganization student movement: the student movement in CEFD/UFSM
}

Reorganización del movimiento estudiantil: el movimiento estudiantil en CEFD/UFSM

\author{
Guilherme Sturmer Lovatto ${ }^{\mathrm{I}}$, Maristela da Silva Souza ${ }^{\mathrm{II}}$
}

\begin{abstract}
Resumo
Neste artigo abordaremos a atuação do Movimento Estudantil de Educação Física no Centro de Educação Física e Desportos da UFSM a partir da reabertura do Diretório Acadêmico (DACEFD) no ano de 2006. Utilizando o método do materialismo histórico e dialético, realizamos uma pesquisa bibliográfica e documental para descrever o processo de reorganização do movimento estudantil e a forma de atuação do MEEF/UFSM através do DACEFD. A atuação do movimento estudantil no DACEFD é expressão do processo de reorganização do movimento estudantil, buscando retomar a atuação baseada na perspectiva classista e combativa dos estudantes.
\end{abstract}

Palavras-chave: Movimento Estudantil; Reorganização do Movimento Estudantil; Movimento Estudantil de Educação Física

\begin{abstract}
In this article we will approach the performance of the physical education student movement at the Physical Education and Sports Center of UFSM from the reopening of the Academic Directory (DACEFD) in 2006. Using the method of historical and dialectical materialism, we will carry out a bibliographical and documentary research to describe the process of reorganizing the student movement and the way in which MEEF / UFSM works through DACEFD. The performance of the student movement in DACEFD is an expression of the process of reorganization of the student movement, seeking to resume action based on the classist and combative perspective of students.
\end{abstract}

Keywords: Student Movement; Reorganization of Student Movement; Student Movement of Physical Education

\footnotetext{
${ }^{\text {I }}$ Universidade Federal de Santa Maria - UFSM - Endereço: Av. Roraima, número 1000, Bairro: Camobi, Prédio 51, Santa Maria, RS. CEP: $97105-900$ - eMail: guilherme.ufsm@gmail.com

II Universidade Federal de Santa Maria - UFSM - e-mail: maristeladasilvasouza@yahoo.com.br
}

\footnotetext{
${ }^{1} \mathrm{O}$ presente artigo é uma síntese do estudo realizado para o trabalho de conclusão do curso de Educação Física licenciatura, defendido no ano de 2013, no Centro de Educação Física e Desportos da UFSM.
} 


\section{Resumen}

En este articulo abordaremos el desempeño del movimiento de estudiantes de educación física en el Centro de Educación Física y Deportes de UFSM desde la reapertura del Directorio Académico (DACEFD) en 2006. Usando el método del materialismo histórico y dialéctico, llevaremos a cabo una investigación bibliográfica y documental para describir el proceso de reorganización del movimiento estudiantil y la forma en que MEEF / UFSM funciona a través de DACEFD. El desempeño del movimiento estudiantil en DACEFD es una expresión del proceso de reorganización del movimiento estudiantil, buscando reanudar la acción basada en la perspectiva clasista y combativa de los estudiantes.

Palabras clave: Movimiento Estudiantil; reorganización del Movimiento Estudiantil; Movimiento de Educación Física Estudiantil

\section{Introdução}

O Movimento Estudantil de Educação Física (MEEF) surge junto à conjuntura de mobilizações do próprio movimento estudantil geral e em escala nacional. As primeiras mobilizações remontam ao ano de 1950, momento de efervescência nacional em torno da luta pelas reformas de base. De acordo com Ferreira (1995), o Centro Acadêmico Ruy Barbosa da USP se colocou contrário à entrada de estudantes nos Cursos de Educação Física através da obtenção apenas do curso de $1^{\circ}$ grau, conseguindo junto ao Ministério da Educação a obrigatoriedade de obtenção também do curso de $2^{\circ}$ grau, o que representava a elevação do padrão de formação da época.

Outra importante mobilização da época foi a greve realizada pelo Diretório Acadêmico da Escola Nacional de Educação Física, a qual objetivava a defesa da democratização da universidade pública, melhor formação em Educação Física, fim de posturas autoritárias por parte de professores e, por fim, a deposição do diretor da escola (CASTELLANI, 1991).

Com essas mobilizações, temos a caracterização de duas bandeiras históricas de luta que articulam e unificam o movimento estudantil a nível nacional. A defesa da Democratização da Universidade Pública, Gratuita, de Qualidade Socialmente Referenciada, e a Defesa de uma Formação em Educação Física de Qualidade, as quais de acordo com a conjuntura e o desenvolvimento da luta de classes tomarão novos contornos ao longo do próprio movimento, apesar de sempre o articularem.

Fruto desse movimento de reivindicações iniciado pelos estudantes, e através da articulação com a União Nacional dos Estudantes, na década de 50, os estudantes de Educação Física criarão a União Nacional dos Estudantes de Educação Física (UNEEF) (FILHO, 1995). 
Com a Ditadura Militar (1964-1989) o movimento estudantil passa a atuar na clandestinidade, muitos setores se envolvem com a luta armada, fazendo com que os registros no que diz respeito à organização estudantil na educação física sejam praticamente inexistentes.

Em 1980, em meio ao processo de reorganização da juventude e da classe trabalhadora, logo após a realização do Congresso da UNE em 1979, o MEEF organiza na cidade de Salvador o $1^{\circ}$ Encontro Nacional de Estudantes de Educação Física (ENEEF).

O MEEF, em vez de assumir uma postura reducionista, opta por articular os debates referentes à área com aquilo que possibilita a articulação dos trabalhadores no processo de combate à ordem vigente. Isto pode ser percebido nos temas ${ }^{2}$ dos seus encontros nacionais realizados nos anos de 1980 , que darão ao MEEF a compreensão de totalidade, o que fará com que este se coloque no combate à ordem vigente a partir das pautas específicas.

No decorrer do processo de apaziguamento da União Nacional dos Estudantes (UNE), vivenciado em meio à luta pelo Fora Collor, em 1992, o MEEF irá, em seu XIII ENEEF, encaminhar a organização da Executiva Nacional de Estudantes de Educação Física, a ExNEEF.

A ExNEEF é uma expressão do processo de reorganização do movimento estudantil. É uma entidade sem fins lucrativos, independente e de duração indeterminada que possui quatro bandeiras de luta que são: a defesa da Universidade Pública, Gratuita, de Qualidade e Socialmente Referenciada; a Licenciatura Ampliada como projeto de formação de professores em Educação Física; a Regulamentação do Trabalho; e o Projeto Histórico de Sociedade Socialista (ExNEEF, 2012). Se estrutura a partir de uma coordenação nacional e seis coordenações regionais que têm o objetivo de articular as bandeiras do MEEF/ExNEEF aos estudantes de todo o Brasil. A forma de atuação frente às bandeiras do Movimento é definida na plenária final do ENEEF e nos debates acumulados pelos Encontros Regionais de Estudantes de Educação Física.

Estes encontros são construídos a partir da base do Movimento Estudantil de Educação Física através de Conselhos Nacionais de Entidades de Educação Física (CoNEEFs) e Conselhos Regionais de Entidades de Educação Física (CoREEFs).

O MEEF/ExNEEF aponta a necessidade de reorganização política a partir da construção de pautas específicas que se articulem com pautas gerais da juventude e dos trabalhadores, reafirmando que antes de reuniões de cúpulas e de direções, em gabinetes e em acordões com governos e reitorias, o que vale para o processo de reorganização é a politização da base.

2 As temáticas dos 15 primeiros ENEEFs foram sistematizada por Ricardo F. Lucena em artigo intitulado "Movimento Estudantil: História e perspectivas" e divulgado no Caderno de Debates da ExNEEF - Volume 03 de Julho de 1995. 
O movimento que aprofundaremos a seguir, de reabertura do Diretório Acadêmico do CEFD/UFSM, faz parte desse movimento mais geral de reorganização da classe trabalhadora, do qual as lutas contra a burocratização e o amoldamento se constituem como elementos centrais do processo. Apesar de o DACEFD ter construído ativamente o Movimento Estudantil de Educação Física nos anos 90, tendo inclusive participado de gestões regionais e nacionais da ExNEEF, o mesmo entrou em um período de inatividade entre os anos de 2001 a 2005. Assim, o período estudado remete aos anos de 2006 a 2012.

\section{Bases teóricas e metodologia}

Neste artigo analisamos como o Movimento Estudantil de Educação Física em âmbito nacional e específico da Universidade Federal de Santa Maria atuou diante da UNE e da política desenhada pelo governo do Partido dos Trabalhadores (PT). Partiremos do momento histórico de reabertura do Diretório Acadêmico do Centro de Educação Física e Desportos (DACEFD) no ano de 2006, e como este tem buscado se diferenciar do projeto de movimento estudantil e juventude que a atual UNE apresenta.

Para darmos prosseguimento metodológico ao trabalho, escolhemos o Materialismo Histórico Dialético, método de análise e compreensão da realidade, formulado por Marx e Engels com o objetivo de contribuir para o desvelamento das contradições da sociedade capitalista e sua possível transformação revolucionária pelos trabalhadores.

As categorias metodológicas do método materialista histórico dialético são: a totalidade, a contradição e a mediação, que possibilitam transcorrer o percurso do concreto empírico, passando por sua forma abstrata, e voltar novamente à forma inicial, porém de modo superior ao ponto de partida, o concreto-pensado (MARX, 2008).

Para além das categorias de método, utilizamos neste trabalho as categorias de análise: Movimento Estudantil, Burocratização, Reorganização do Movimento Estudantil, e Movimento Estudantil de Educação Física.

Sob os pressupostos das referidas categorias, utilizamos como técnica de estudo a pesquisa bibliográfica e documental para descrever o processo de burocratização da UNE e a forma de atuação do MEEF/UFSM através do DACEFD. De acordo com Gil (2008, p.50): 
A pesquisa bibliográfica é desenvolvida a partir de material já elaborado, constituído principalmente de livros e artigos científicos. Embora em quase todos os estudos seja exigido algum tipo de trabalho desta natureza, há pesquisas desenvolvidas exclusivamente a partir de fontes bibliográficas. Partes dos estudos exploratórios podem ser definidas como pesquisas bibliográficas, assim como certo número de pesquisas desenvolvidas a partir da técnica de análise de conteúdo.

Dessa forma, como instrumento de análise bibliográfica, utilizamos livros, teses e dissertações que trazem o histórico da UNE e analisam tanto a sua atuação no contexto da realidade brasileira como também a sua relação com o Estado e os Partidos Políticos.

Longe de se diferenciar da forma de estudo que a pesquisa bibliográfica nos aponta, realizamos o estudo documental, que visa, segundo Gil (2008), realizar a análise de documentos que ainda não receberam um tratamento analítico, como é o caso de atas de reuniões, assembleias, panfletos e órgãos superiores do CEFD e da UFSM, para identificar o modo de atuação do MEEF na cidade de Santa Maria.

\section{Movimento Estudantil de Educação Física: Atuação na UFSM}

Após um ano fechado, no qual os estudantes do CEFD/UFSM não possuíam voz coletiva, inclusive não podendo participar dos ínfimos debates que deram seguimento à fragmentação curricular no CEFD, o DACEFD é reaberto no ano de 2006, quando da participação de estudantes no XII EREEF realizado na UFRGS.

Deste Encontro, do qual o tema "Do espetáculo do Esporte à realidade do trabalho: as mãos que constroem o país levantam a taça?" debateu o esporte tendo em vista a realização dos Jogos PanAmericanos de 2007 no Brasil e sua relação com o Mundo do Trabalho, além é claro das bandeiras de atuação do MEEF/ExNEEF, os estudantes de Santa Maria retornaram com a tarefa de reorganizar o DACEFD.

No ano de 2006, aos 26 dias de outubro, foi iniciado em assembleia autoconvocada pelos estudantes o processo eleitoral para a reabertura de entidade. Neste processo estabeleceram-se duas chapas, uma delas a Instinto Coletivo com forte ligação com o MEEF, a ExNEEF e suas bandeiras, a qual foi eleita com 120 votos a favor, contra 84 votos para a chapa 2, conforme a ata do DACEFD n 1 de 2006.

No mesmo ano, objetivando trabalhar com a formação política do coletivo, dá-se início aos Grupos de Estudo (GE). Os GEs serão ministrados pelos próprios estudantes e buscarão trazer temas que 
digam respeito às bandeiras do MEEF, como também outras questões referentes à área da Educação Física. O primeiro GE acontece com a temática da Formação em Educação Física.

No ano de 2007, ainda durante a gestão Instinto Coletivo, iniciam as Calouradas, que objetivam dar as boas vindas aos ingressantes na universidade e com isso apresentar-lhes o movimento estudantil e suas bandeiras. Além disso, a gestão organizará seu primeiro jornal.

No mesmo ano, o DACEFD participará do XIII EREEF que ocorre na cidade de Florianópolis com o tema "Robôs declarados e seres alienados!?" É essa prática que eu não quero seguir admitindo", onde se realizaram debates em relação a projeto de sociedade, formação em educação e atuação do movimento estudantil.

Nas eleições para o DCE da UFSM no ano de 2007 a gestão Instinto Coletivo do DACEFD não compõe nenhuma das chapas, mas sai em apoio à chapa 3, constituída por setores do Partido Socialismo e Liberdade (PSOL) e Independentes, a qual trazia a necessidade de debater os rumos da contrarreforma universitária e pensar ações para mudar os rumos do movimento estudantil. O DACEFD é um dos primeiros setores do movimento estudantil que rompem com a política de movimento estudantil capitaneada por setores ligados ao Partido dos Trabalhadores.

No XVIII ENEEF, realizado na UFPB em 2007, será encaminhado na plenária final ${ }^{3}$ do Encontro a deliberação de discutir a ruptura da ExNEEF com a UNE a partir das instâncias do movimento (ExNEEF, DELIBERAÇÕES DO XXVIII ENEEF, 2007). Esta deliberação dará continuidade ao debate já iniciado no MEEF sobre o papel que a UNE desempenha e também abrirá possibilidade para que se retome a necessidade de um movimento estudantil que seja autônomo a governos, partidos e que atue em contraposição à ordem vigente.

Percebe-se a necessidade de debater a formação em Educação Física de forma mais central no CEFD, já que os estudantes vinham trazendo diversas críticas em relação à divisão do curso em Licenciatura e Bacharelado ocorrida no ano de 2005, tendo em vista também a participação do diretório no processo de reformulação curricular que tinha objetivo de corrigir problemas nos dois cursos.

Em conjunto com o movimento estudantil a nível nacional, o DACEFD, em assembleia realizada no ginásio do CEFD no dia 18 de outubro de 2007 (ata $\mathrm{n}^{\circ} 3$ do ano de 2007), da qual os professores também participaram, aprova após amplo debate a contrariedade ao projeto REUNI e sua implementação. O CEFD e o Centro de Educação (CE) foram os únicos centros que realizaram a discussão em torno da expansão via REUNI em toda a UFSM. Apesar disso, o CEFD, em votação realizada no Conselho de

${ }^{3} \mathrm{O}$ conjunto de deliberações deste ENEEF pode ser acessado em http://www.caef.cds.ufsc.br/exneef/arqs/deliberaufpb.pdf 
Centro, dá parecer favorável ao REUNI (BRASIL, 2007, Ata $\mathrm{n}^{\circ} 412$ do Conselho do CEFD). Sua implementação ocorrerá através dos Pareceres 220 e 221, os quais tratam do aumento de $10 \%$ de vagas para cada curso (BRASIL, 2008, Ata $\mathrm{n}^{\circ} 416$ do Conselho do CEFD). Neste mesmo ano realiza-se uma ocupação de reitoria, a qual o DACEFD compõe, e que entre outras pautas estruturais da universidade trazia para um setor do movimento estudantil a necessidade de debate em torno do REUNI.

Buscando ampliar as discussões que já vinham sendo realizadas junto aos estudantes, em novembro de 2007 ocorre a VIII Semana Acadêmica com o tema "Difícil é Romper as Amarras, a Educação Física lutando por sua essência”, que contou com a participação de quatro coordenadores nacionais da ExNEEF e trouxe como eixo a formação em Educação Física e o papel do esporte na sociedade.

De acordo com o Parecer dos Grupos de Estudos sobre Diretrizes Curriculares Nacionais da VIII Semana Acadêmica:

A partir dessa relatoria, e deste aprofundamento na discussão sobre diretrizes curriculares, o Diretório Acadêmico conclui que os estudantes entendem pela necessidade de uma REFORMA CURRICULAR com urgência, que aponte para o reagrupamento dos cursos de Licenciatura e Bacharelado, tendo em vista priorizar a formação do professor ou profissional que entraram aqui para ser. (BRASIL, anexo II, 2007).

Passada a VIII Semana Acadêmica, realiza-se nova eleição para o DACEFD, a qual contou com a inscrição de apenas uma chapa de situação e elegeu a gestão "Luta Coletiva".

No XIV EREEF realizado em Curitiba em 2008 - "Educação Física no Mundo do Trabalho: quanto vale ou é por quilo?” - o DACEFD será apontado por diversas escolas da regional como a próxima sede do XV EREEF. O ENEEF de Porto Alegre realizado em 2009, o qual debateu os ataques do projeto REUNI, a regulamentação do trabalho e a contrariedade ao sistema CONFEF/CREF, teve como tema "Professora e professor regulamentado e a educação se ajoelhando para o mercado. Vamos à luta para acabar com esse reinado" e é um marco do Movimento Estudantil de Educação Física. Neste, que contou com um ato articulado com a Federação dos Estudantes de Agronomia do Brasil e o MST, a ExNEEF rompe com a UNE após debater seu papel durante um ano de gestão em todos os seus fóruns.

Com esta deliberação e dotados da tarefa de construir o XV EREEF em Santa Maria, o coletivo de estudantes do DACEFD volta às bases com o objetivo de potencializar a luta estudantil. Neste mesmo ano, o DACEFD construiu a IX Semana Acadêmica do CEFD/UFSM, que tinha como objetivo aprofundar o debate em torno da regulamentação da profissão, da ingerência do sistema CONFEF/CREF e da formação em Educação Física. 
Esta Semana, que teve como tema "A Educação Física fragmentada e a profissão regulamentada. Contra essa farsa, por uma formação ampliada" e contou com a presença da Professora Celi Taffarel e do vice-presidente do CONFEF, o professor João Batista Tojal, demonstrou o acirramento da luta em torno de projetos antagônicos de Educação Física no CEFD/UFSM, e a possibilidade de potencializarmos a pauta de formação e currículo em Educação Física.

Conforme ata $\mathrm{n}^{\mathrm{o}} 11$ de 2008, a chapa "Lutar sem perder a ternura jamais" é eleita com 141 votos a favor contra 8 votos contrários, demonstrando que a política traçada se colocava inserida na base estudantil.

Realizamos o XV EREEF que teve como tema "Formação em Educação Física: Fechado para Balanço!", o qual debateu a regulamentação da profissão, a formação em Educação Física e a criminalização dos movimentos sociais e consolidou o coletivo de estudantes do DACEFD junto às escolas da regional, contribuindo para a organização interna do movimento estudantil no CEFD.

Com novos acúmulos políticos e organizativos damos continuidade à luta em torno da reestruturação curricular, ocupando no começo de maio de 2009 o Conselho de Centro com cerca de 80 estudantes para exigir que o CEFD paralisasse suas atividades por três dias para discutir os rumos da formação. Ao final deste espaço encaminhou-se em plenária final a deliberação de que o CEFD iniciaria a reestruturação curricular, visando à constituição de um único curso de Educação Física através de uma comissão paritária.

Por conta da força e organização estudantil, tivemos assim, pela primeira vez na história do CEFD, a constituição de uma comissão paritária para dar prosseguimento à unificação curricular, conforme a ata $\mathrm{n}^{\circ} 424$ do Conselho do Centro:

O prof. Carlos Bolli contextualizou os avanços obtidos dizendo que recebeu um indicativo para a constituição de uma comissão para dar andamento à construção de um único curso, cabendo ao conselho definir os membros que irão constituir tal comissão. Após diversas discussões ficou estabelecido que a comissão será formada por um representante de cada departamento e coordenação, um representante técnico administrativo e quatro representantes estudantis. (BRASIL, 2009, p. 2).

Com este encaminhamento, o movimento estudantil passa a apresentar elementos que identificam a proposta de formação construída pelo Movimento Estudantil de Educação Física, que é a Licenciatura Ampliada. Realizamos com o conselheiro do Conselho Nacional de Educação, professor Paulo Barone, da Universidade Federal de Juiz de Fora (UFJF) uma mesa de debates com o tema "Reestruturação 
Curricular: formação e atuação profissional em Educação Física ${ }^{4 ”}$.

O DACEFD participa do XXX ENEEF, que teve como tema "Educação Física em tempos de crise: a formação para além dos muros da universidade". Nele é lançada a campanha "Educação Física é uma só! Formação Unificada JÁ!”, a qual surge da necessidade de debates junto à base dos estudantes no processo de reorganização da ExNEEF e do Movimento Estudantil após o rompimento com a UNE.

O DACEFD volta a Santa Maria com a tarefa de reestruturar suas bases organizativas para dar continuidade à luta iniciada em torno da formação em Educação Física e implementar na UFSM a campanha construída a nível nacional. Realizamos um espaço de formação ${ }^{5}$ interno e de planejamento, no qual damos início à constituição de um coletivo estruturado sob princípios organizativos, valores militantes, métodos de análise e atuação na realidade.

Deste espaço tiramos o encaminhamento de construir no CEFD a campanha "Educação Física é uma só! Formação Unificada JÁ!”, a qual será lançada em assembleia estudantil no dia 9 de setembro de 2009 e terá como símbolo a mão esquerda com o dedo em riste, diferente da arte da campanha lançada pelo ENEEF - uma roda dentada com diversos elementos como a foice e o martelo, a universidade, a capoeira - e que na nossa compreensão não dialogava com o conjunto dos estudantes. No planejamento da ExNEEF da gestão 2009/2010 se altera a arte da campanha, sendo utilizada a arte que criamos no DACEFD.

Podemos perceber que a construção do MEEF e da ExNEEF realiza-se em seus espaços de construção e deliberação a nível nacional, mas de acordo com os debates e as demandas que são apresentadas pela base consciente dos estudantes. Contrapõe-se assim ao estilo burocrático estabelecido na União Nacional dos Estudantes.

Ao final do ano realiza-se mais uma eleição para o Diretório Acadêmico, novamente com chapa única e que contou com a eleição da chapa “A Luta é pra vencer!”, que tomou posse aos 17 dias do mês de dezembro.

Em 2010, após a conquista da Comissão de Reestruturação Curricular Paritária, dá-se início à construção da proposta de reestruturação curricular, visando à unificação baseada na proposta de formação construída pelo MEEF, a Licenciatura Ampliada.

\footnotetext{
4 A palestra do professor pode ser acessada pelo link http://www.youtube.com/watch?v=ouvvvHyE6C4, bem como a propaganda do espaço convocado pelo DACEFD em http://dacefdufsm.blogspot.com.br/2009/07/palestra-com-paulobarone.html

${ }^{5}$ Estes espaços se tornarão elementos centrais da organização e construção do coletivo de estudantes do CEFD. Passarão a ser realizados semestralmente e com a presença de professores e militantes que já passaram pelo movimento estudantil. Outro importante espaço é a Linha de Estudos Epistemológicos e Didáticos em Educação Física (LEEDEF), apesar de não tirarem linha política de atuação para ela.
} 
O coletivo de estudantes do CEFD/UFSM passa a realizar diversas atividades em torno da campanha "Educação Física é uma só! Formação Unificada JÁ!" como rodas de capoeira, mateadas, que buscavam fortalecer a campanha junto à base estudantil. Neste momento, a campanha passa a tomar centralidade nas ações do DACEFD, que participando ativamente das reuniões de reestruturação curricular, esperava ao final da formulação da proposta de Licenciatura Plena de Caráter Ampliado, potencializar o enfrentamento junto aos estudantes.

Esta tática pode ser identificada quando da construção da X Semana Acadêmica, a qual se colocou a debater os eixos de universidade e licenciatura ampliada, e tinha como objetivos socializar a proposta de formação construída pela Comissão de Reestruturação Curricular e fortalecer o coletivo para a construção do XXXII ENEEF que viria a se realizar em Santa Maria.

A tática de fortalecer espaços burocráticos para depois voltar com acúmulo de vitórias à base, para apresentar as possibilidades concretas da luta, vem demonstrando que quando as direções do movimento, como é o caso do DACEFD, voltam às bases acaba por existir um espaçamento, certas vezes um abismo, entre os interesses das direções e as necessidades da base estudantil.

Isto pôde ser comprovado na realização da X Semana Acadêmica do CEFD, onde muitos estudantes, por não terem acompanhado o processo de debate e construção que a Comissão realizou, se colocaram de forma contrária à proposta organizando uma oposição apoiada pela direção do CEFD.

Mesmo como oposição, esta não se colocou a organizar uma chapa contrária para concorrer à eleição da entidade no ano de 2010. O coletivo do DACEFD é reeleito, tendo um total de 140 votos favoráveis à chapa “Todos Somos Um!” e 76 votos contrários.

Em 2011 demos prioridade à construção do XXXII ENEEF que teria como eixo de debates a Licenciatura Ampliada e a Universidade. Esta construção tinha como objetivo reaproximar o DACEFD dos estudantes, buscando consolidar novos militantes junto à entidade, dando continuidade à política desempenhada pelo movimento estudantil no CEFD. Constitui-se uma comissão organizadora composta de cerca de 30 pessoas, a qual se inseriu no processo de construção não somente do XXXII ENEEF, mas também do próprio DACEFD.

Em meio a esta construção, realizamos o Plebiscito em defesa da Formação Unificada, o qual foi construído a nível nacional pelo MEEF/ExNEEF e, conforme o II Boletim da Campanha ${ }^{6}$, teve um montante de 2341 votos favoráveis à Licenciatura Ampliada contra 160 votos contrários e 7 nulos, e no

6 O Boletim com a votação específica de cada escola pode ser acessado em http://www.exneef.libertar.org/wpcontent/uploads/2011/09/Boletim-da-Campanha.pdf 
CEFD contou com a participação de 223 estudantes, dos quais 151 votos favoráveis à Licenciatura Ampliada, 67 votos contrários e 5 votos nulos.

Em meio ao processo de construção do ENEEF, fruto da precarização da universidade federal, os servidores técnico-administrativos se colocam em greve pela defesa de reposição salarial e plano de carreira, fazendo com que o Restaurante Universitário (RU) permaneça fechado até o mês de agosto. O coletivo de estudantes do DACEFD constrói espaços para junto dos estudantes debater a greve e demonstrar qual o papel do movimento estudantil junto à luta dos trabalhadores.

Realizam-se diversos almoços no diretório acadêmico, momentos em que aconteciam debates a respeito dos motivos da greve e se reafirmava a necessidade do movimento estudantil apoiar o movimento grevista, colocando-se contrários ao projeto neoliberal de educação colocado em prática.

O XXXII ENEEF é realizado entre os dias 17 e 24 de Julho de 2011 encampando o tema "Formação Unificada e Universidade: o Movimento Estudantil disputando os rumos da sociedade". Neste, a ExNEEF reafirma o papel da campanha “Educação Física é uma só! Formação Unificada JÁ!”, o combate à política educacional do governo Lula/Dilma/PT e rompimento com a UNE.

Ao final do ENEEF, as contradições decorrentes da implementação do projeto de contrarreforma universitária de Lula/Dilma/PT, dos quais o REUNI é o carro-chefe, passam a ser explicitadas por outros setores do movimento estudantil da UFSM. Assim, em Assembleia Geral de Estudantes organizada pelo DCE, os estudantes de Medicina e Terapia Ocupacional, radicalizados pelas condições precárias de estrutura e formação, pautam a ocupação da reitoria ${ }^{7}$. A ocupação durou 13 dias, trouxe diversas pautas que expunham os problemas da falsa expansão advinda do REUNI e fez parte da série de 16 ocupações que agitaram as universidades federais no ano de 2011. Com o fim da ocupação, o coletivo de estudantes do DACEFD se coloca a construir os Jogos de Integração da Educação Física (JOINTEF), articular o “Plebiscito Nacional pelos 10\% do PIB para a Educação Pública Já!” junto às pautas de precarização da universidade e o Boicote ao ENADE.

Na construção do plebiscito, o coletivo não foi capaz de organizar nenhum espaço de formação como mesas ou rodas de debate. Assim, construiu-se uma pauta importante para o conjunto do movimento estudantil e da classe trabalhadora, mas não a articulamos com o específico do CEFD e com o que diz respeito à necessidade de formação política da base de estudantes.

Fruto do processo que estabelecemos em relação à Comissão de Reestruturação Curricular e à pauta da Licenciatura Ampliada, o coletivo de estudantes do DACEFD passou a atuar sem realizar

${ }^{7} \mathrm{O}$ conjunto de reivindicações da Ocupação da Reitoria da UFSM, juntamente às notas públicas de apoio pode ser acessado em http://ocupacaoreitoriaufsm.wordpress.com/. Constata-se que não houve apoio da UNE à ocupação. 
nenhuma mediação entre o específico dos estudantes e o geral da luta de classes. Amplia-se a distância entre os membros do diretório acadêmico e os estudantes. Esses limites manifestam-se no nome da chapa eleita em 2011, "Lutar quando é fácil ceder!”.

Este processo expõe a necessidade de avaliar a reestruturação curricular, o trabalho interno na Comissão e a campanha “Educação Física é uma só!”. A partir de Grupos de Estudos os estudantes decidem retirar-se da Comissão de Reestruturação Curricular, apontando como prioritária a mobilização e organização estudantil na base dos estudantes.

O coletivo de estudantes do DACEFD apontou que a luta dos estudantes deve estar articulada com a luta mais geral que o movimento estudantil vinha travando contra a contrarreforma universitária, negando a possibilidade de atuação, disputa e fortalecimento de espaços burocráticos como é a disputa de currículos de formação e de comissões de reestruturação. Com isso, o DACEFD acaba por afirmar a necessidade de ruptura da esquerda com o Projeto Democrático Popular.

Em meio ao processo de debates e balanço interno que vinha sendo construído pelo coletivo de estudantes do DACEFD, os professores e servidores técnico-administrativos entram em greve no primeiro semestre de 2011, em reivindicação por reajustes salariais e reestruturação do plano de carreira. Junto a este movimento, que atingiu 48 instituições federais de ensino, os estudantes por fora da UNE também se colocaram em greve em 16 instituições de ensino, demonstrando que aquilo que era falado sobre o projeto do REUNI no ano de 2007 se comprovava na prática.

Neste movimento, o coletivo de estudantes do DACEFD se insere nos espaços de construção da greve estudantil e de professores na UFSM. Esta inserção foi debatida em Assembleia Estudantil do CEFD, a qual tirou apoio irrestrito à greve dos professores, apontando ainda a necessidade de debater a greve estudantil e sua relação com os problemas estruturais que o CEFD vinha enfrentando.

Com a compreensão do balanço construído para a saída do coletivo de estudantes da Comissão de Reestruturação Curricular, o qual se tornara público no CEFD através de nota lida e aprovada em assembleia geral, apenas após o ENEEF Santa Maria, o coletivo de estudantes do DACEFD se encaminha para o XXXIII Encontro Nacional de Estudantes de Educação Física, construído na Universidade Estadual de Feira de Santana - BA (UEFS), o qual teve como eixo "Se o presente é de luta, o futuro nos pertence! - ExNEEF 20 anos".

O coletivo de estudantes do DACEFD se volta novamente à base dos estudantes do CEFD com a tarefa de retomar a luta dos estudantes em defesa da universidade pública e de outro modelo de formação. Realiza, assim, a XI Semana Acadêmica do CEFD UFSM, com o tema "O CEFD em Questão, o 
estudante pensando os rumos da Universidade e da Formação", a qual conta com a construção de uma Comissão Organizadora que atinge o montante de 30 pessoas.

Ao final da Semana Acadêmica os estudantes reunidos em assembleia encaminham à Direção do CEFD a Carta de Reivindicações da XI Semana Acadêmica exigindo a solução de problemas estruturais e de formação e reafirmando que a luta do Diretório Acadêmico e do movimento estudantil deve se dar a partir da oposição às políticas educacionais e em defesa de outro projeto de sociedade, sendo assim, deve se dar com os estudantes conscientemente mobilizados e organizados, e não pela representatividade dos estudantes em reuniões de gabinetes e acordos com governos, reitorias e direções de centro.

\section{Conclusão}

Ao longo destes momentos, retomamos a forma e o conteúdo com o qual o coletivo de estudantes de Educação Física que compunha o DACEFD, nos anos de 2006 até 2012, atuou frente aos processos de luta que ocorreram tanto no específico do CEFD da UFSM - e que fizeram com que o mesmo se situasse no cenário nacional de construção do Movimento Estudantil de Educação Física - como também no cenário mais geral de atuação do movimento estudantil na UFSM, através da oposição aos setores que compunham o DCE da instituição.

Percebemos que o DACEFD por ser parte da reorganização do movimento estudantil e da classe trabalhadora reproduziu, guardadas as suas especificidades, os elementos que constituem o ciclo de lutas do projeto democrático e popular.

O coletivo de estudantes de Educação Física do CEFD/UFSM que esteve à frente do DACEFD buscou na retomada do trabalho de base, no combate às políticas governamentais, na formação e politização dos estudantes e na crítica ao amoldamento da UNE e do PT contribuir para a superação do projeto citado e de suas ferramentas, como, também, para o fortalecimento do MEEF em sua autonomia classista e democrática.

\section{Referências}

CASTELLANI FILHO, Lino. Educação Física no Brasil: a história que não se conta. 2. ed. Campinas, SP: Papirus, 1991.

DACEFD, UFSM. Ata n⿳ 1 da Assembleia dos Estudantes do CEFD. Caderno de Atas, 2006.

DACEFD, UFSM. Ata no 3 da Assembleia dos Estudantes do CEFD. Caderno de Atas, 2007. 
DACEFD, UFSM. Ata no 11 da Assembleia dos Estudantes do CEFD. Caderno de Atas, 2008.

ExNEEF. Carta de Apresentação da Gestão da ExNEEF 2012/2013. Disponível em: http://www.exneef.libertar.org/?p=290 Acesso em: 22 jan. 2013

ExNEEF. Deliberações da Plenária Final do XXVIII ENEEF. Disponível em: http://www.caef.cds.ufsc.br/exneef/arqs/deliberaufpb.pdf Acesso em: 21 jan. 2013.

FERREIRA, Marcelo Guina. Movimento Estudantil de Educação Física: em busca de raízes históricas. Uma breve reflexão. In. Caderno de Debates ExNEEF, vol. 3, p. 31-36, 1995.

FILHO, Nelson Figueiredo de Andrade. Movimento Estudantil: a luta por perspectiva, a história por consagração. Caderno de Debates ExNEEF, vol. 3, p. 15-24, 1995.

GIL, Antonio Carlos. Métodos e técnicas da pesquisa social. 6. ed. São Paulo: Atlas, 2008.

MARX, Karl. Contribuição à Crítica da Economia Política. Tradução e introdução de Florestan Fernandes. 2. ed. São Paulo: Expressão Popular, 2008.

UFSM. Centro de Educação Física e Desportos. Ata no 424 do Conselho do Centro de Educação Física e Desportos. Santa Maria, 2009.

UFSM. Centro de Educação Física e Desportos. Ata no 412 do Conselho do Centro de Educação Física e Desportos. Santa Maria, 2007a.

UFSM. Centro de Educação Física e Desportos. Comissão de Reestruturação Curricular do Centro de Educação Física e Desportos. Anexo II - Parecer dos GEs sobre Diretrizes Curriculares Nacionais da VIII Semana Acadêmica. Santa Maria, 2007b.

\section{Como citar este artigo}

LOVATTO, G. S.; SOUZA, M. S. Reorganização do Movimento Estudantil: o Movimento Estudantil no CEFD/UFSM. Revista Kinesis, Santa Maria, Dossiê CEFD 50 anos, p.01-14, 2020.

* O presente trabalho não contou com apoio financeiro de nenhuma natureza para sua realização. 